\title{
EXPERIENCE ON THE HIGH-POWER SiC MICROWAVE DUMMY-LOAD USING SiC ABSORBER
}

\author{
H. Matsumoto, KEK; Y. Iino, C. Fujiwara, Z. Kabeya, T. Onda; Mitsubishi Heavy Industries Ltd., Japan
}

\section{Abstract}

A new type microwave dummy-load using Silicon Carbide (SiC) ceramic, which has an indirect water cooling structure, was successfully operated with up to 50-MW of rf power at a 1- $\mu$ s pulse width and 50-pps repetition rate in the S-band frequency. The input VSWR obtained was less than $1: 1.1$ at the maximum rf power. The vacuum pressure in the rf-load raised from the base pressure of $1 \times 10^{-6} \mathrm{~Pa}$ with no rf power to $2 \times 10^{-6} \mathrm{~Pa}$ at the maximum rf-power; and there was found to be no special out gassing from the SiC-ceramics.

\section{INTRODUCTION}

Our first microwave dummy-load using $\mathrm{SiC}$-ceramic was originally developed for an S-band $2.5-\mathrm{GeV}$ electron linac at KEK in 1980, and has been used for 17 years without trouble. The old model SiC-dummy-load used a direct water cooling method, because there was no brazing method available due to the big difference in thermal expansion coefficients of $\mathrm{SiC}$ and Oxygen-Free-Copper.

The upgraded version of the S-band dummy-load using brazed rod-shaped $\mathrm{SiC}$ pieces for the high peak power microwave absorber was developed in 1993 during the course of R\&D for the e+e- Japan Linear Collider (JLC). It will be used for the more than 10,000 dummyloads in the rf system for $500 \mathrm{GeV}$ C.M. version accelerator [1]. Because of the large numbers, increased reliability and cost reduction become very important design considerations. Therefore, I decided to use an indirect water cooling method instead of the previous direct cooling. In 1995 at KEK, the resulting design was tested up to a maximum input $\mathrm{rf}$ power of $50 \mathrm{MW}, 1 \mu \mathrm{sec}$ pulse width and 50 pps repetition rate.

The new type SiC-dummy-loads have already been in use on the KEKB $8 \mathrm{GeV}$ electron linac ( 250 pieces) since 1998 [2, 3]; a photograph is shown in Figure1.



Figure 1: Indirect water cooling type SiC-dummy-load for the KEKB $8 \mathrm{GeV}$ electron linac.

The SiC-ceramic rods are brazed along both narrow inner walls of the rectangular wave-guide; the overall length is less than $45-\mathrm{cm}$. Two water channels are welded to both narrow outer walls of the wave-guide.

The final design targets for the dummy-load for the JLC are listed in Table 1.

Table 1: Target specifications of the SiC-dummy-load for the 500-GeV C.M. version of JLC.

\begin{tabular}{|l|r|r|r|}
\hline & Achieved & \multicolumn{2}{|c|}{ Final goal } \\
\hline Frequency $(\mathrm{MHz})$ & 2856 & $2856^{1)}$ & $5712^{2)}$ \\
\hline Peak input rf power $(\mathrm{MW})$ & 50 & 50 & 50 \\
\hline RF pulse width $(\mu \mathrm{sec})$ & 1.0 & 1.0 & 0.5 \\
\hline RF pulse repetition rate $(\mathrm{pps})$ & 50 & 150 & 150 \\
\hline Physical length $(\mathrm{m})$ & $<1.0$ & $<1.0$ & $<1.0$ \\
\hline
\end{tabular}

Note: 1) pre-injector. 2) main linac. Common specifications: in vacuum, indirect water-cooling and within the 1:1.1 of VSWR.

This paper will describe the basic characteristics of the $\mathrm{SiC}$-ceramic and the high power experimental test results.

\section{BASIC CHARACTERISTICS OF THE SiC CERAMIC}

$\mathrm{SiC}$ powders can crystallize into either $\alpha$ - or $\beta$-forms. I choose the $\beta$-crystallization $\mathrm{SiC}$ powder to reduce the variation in microwave loss-tangent after the sintering process. The $\beta$-crystallized $\mathrm{SiC}$, which has a good uniformity of powder size is produced by a chemical reaction between silicon-dioxide $\left(\mathrm{SiO}_{2}\right)$ and carbon-black (3C) powder at a temperature range of 1500 to $1800{ }^{\circ} \mathrm{C}$ in an inert gas atmosphere. The reaction can be expressed as

$$
\mathrm{SiO}_{2}+3 \mathrm{C}=\mathrm{SiC}+2 \mathrm{CO} .
$$

$\mathrm{SiC}$-ceramic is then made from the $\mathrm{SiC}$ power by sintered in a vacuum furnace at a $2100{ }^{\circ} \mathrm{C}$ temperature [4]. The basic characteristics of the SiC-ceramic are listed in table 2.

Table: 2 Basic characteristics of the SiC-ceramic.

\begin{tabular}{|l|c|l|}
\hline Density $\left(\mathrm{g} / \mathrm{cm}^{3}\right)$ & 3.14 & \\
\hline $\begin{array}{l}\text { Hardness } \\
\left(\text { Knoop, } \mathrm{kgf} / \mathrm{mm}^{2}\right)\end{array}$ & 2900 & at $\mathrm{RT}^{1)}$ \\
\hline $\begin{array}{l}\text { Thermal conductivity } \\
\left(\mathrm{cal} / \mathrm{cm} \cdot \mathrm{sec}^{\circ} \mathrm{C}\right)\end{array}$ & $\begin{array}{l}0.19 \\
0.14\end{array}$ & $\begin{array}{l}\text { at } \mathrm{RT}^{1)} \\
\text { at } 600{ }^{\circ} \mathrm{C}\end{array}$ \\
\hline $\begin{array}{l}\text { Thermal expansion } \\
\text { coefficient }\left({ }^{\circ} \mathrm{C}^{-1}\right)\end{array}$ & $4.6 \times 10^{-6}$ & $\mathrm{RT}^{1)}$ to $1200^{\circ} \mathrm{C}$ \\
\hline $\begin{array}{l}\text { Oxidation weight gain } \\
\left(\mathrm{mg} / \mathrm{cm}^{2}\right)\end{array}$ & 0.015 & at $1200^{\circ} \mathrm{C}$ for 24 hours \\
\hline $\begin{array}{l}\text { DC Resistively } \\
(\Omega \cdot \mathrm{cm})\end{array}$ & $5 \times 10^{5}$ & at $\mathrm{RT}^{1)}$ \\
\hline at $800^{\circ} \mathrm{C}$ \\
\hline Dielectric constant & $30 \sim 35$ & 0.5 to $20 \mathrm{GHz}^{2)}$ \\
\hline Loss tangent & $0.3 \sim 0.5$ & 0.5 to $20 \mathrm{GHz}^{2)}$ \\
\hline
\end{tabular}

Note: 1) RT: Room Temperature, 2) The measured frequency range is limited by the network analyzer. 
Figures 2 and 3 show the variations in dielectric constant and loss tangent of some SiC-ceramic samples, for the KEKB dummy-load. This result shows that the variation of both parameters (dielectric constant and loss) are dependent on amount of sintering binders, since the binder is evaporated from the SiC-ceramic during the second sintering process.

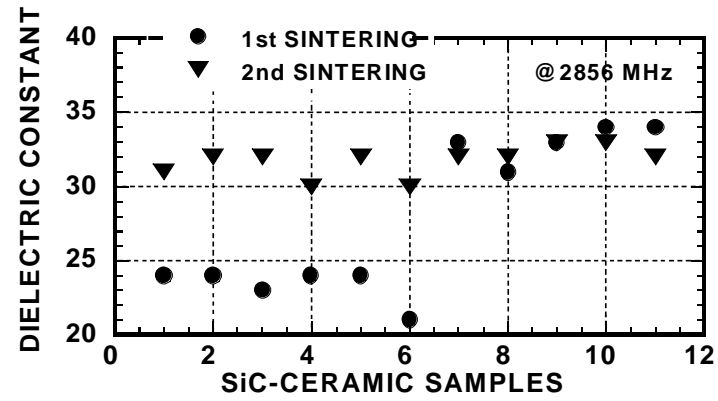

Figure 2: Variations of the dielectric constant of SiC-ceramic samples after one and two sintering cycles.

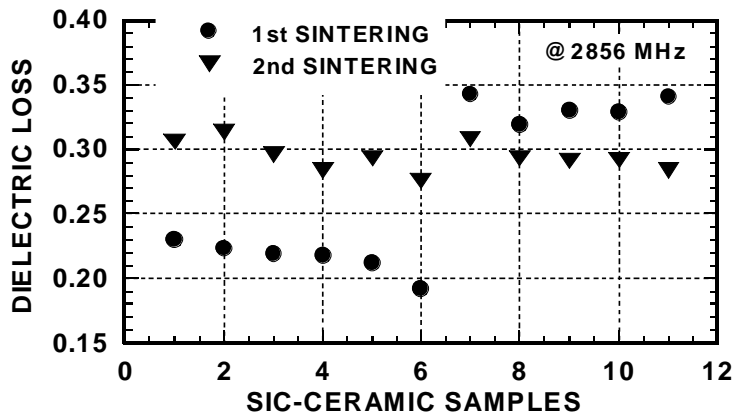

Figure 3: Variations of the dielectric loss of SiC-ceramic samples after one and two sintering cycle.

\section{DUMMY-LOAD DESIGN}

An important design consideration is that the structure be as simple as possible; this includes the shape of $\mathrm{SiC}$ ceramic absorber, housing and cooling structures. I decided to use a conventional S-band rectangular waveguide for the housing, with a $7.21-\mathrm{cm} \times 3.4-\mathrm{cm}$ cross section and a 5-mm wall thickness. Simple rod shaped $\mathrm{SiC}$-ceramics each $2-\mathrm{cm}$ in diameter were chosen for the microwave absorbers; they are brazed to the inner wall on the narrow side of the wave-guide as shown in Figure 4 [5].

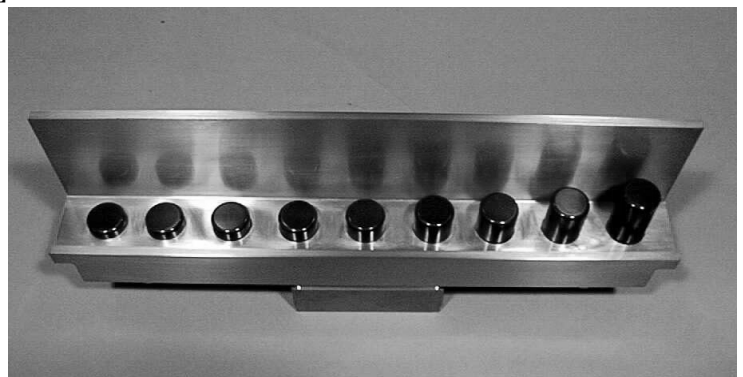

Figure 4: Cut-away view of the SiC-dummy-load. The SiCceramic absorbers brazed on the narrow wall $(3.4-\mathrm{cm})$ of the conventional S-band rectangular wave-guide are black in color. All the SiC-ceramic absorbers have the same 2-cm diameter.
The design arrives at a compromise to obtain an input VSWR of less than 1:1.1 while keeping the temperature rise at the top of each $\mathrm{SiC}$-ceramic rod below $30{ }^{\circ} \mathrm{C}$; both at the maximum operation condition $(2.5-\mathrm{kW}$ average power). The input VSWR was minimized by adjusting the spacing between the $\mathrm{SiC}$-ceramic rods using a simple quarter-wave impedance matching method as shown in Figure 5. It was still necessary to experimentally tune the $\mathrm{SiC}$ positions to minimize the input VSWR of below 1:1.1. Figure 6 shows typical characteristics of the reflection coefficient (S11) as a function of the distance between $\mathrm{SiC}$-ceramic rods.

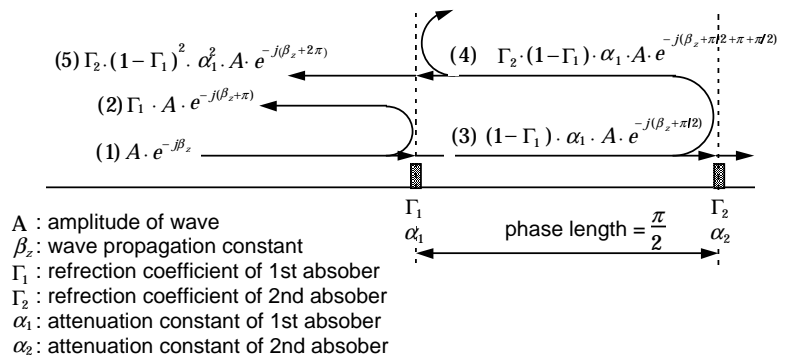

Figure 5: Principle of quarter-wave impedance matching method for locating the SiC-ceramic absorbers. The second reflection wave between $\mathrm{SiC}$-ceramic rods is ignored because the amplitude is already very small.

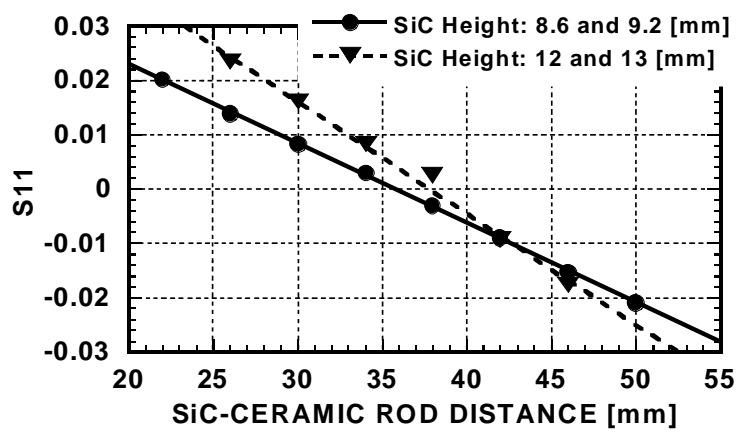

Figure 6: Variation of the reflection coefficient (S11) as a function of the distance between $\mathrm{SiC}$-ceramic rods. The zero cross point in S11 appears roughly a quarter-wave length at 2856-MHz. Position sensitivity on the SiC-ceramic height is due to superimposition of the large reflection vectors.

We calculated the temperature rise between bottom and top of the SiC-ceramic absorbers using steady state thermal conducting theory based on an attenuation curve along the axis of the dummy-load and the measured rf power loss per cubic centimeter of ceramic absorber.

Figure 7 shows the first high-power model S-band dummy-load. A total of $28 \mathrm{SiC}$-ceramic rods are brazed to the narrow walls of the rectangular wave-guide housing. Two water channels attach to both narrow walls and the typical flow rate for the cooling water is 20 liters per minute. In this case, the maximum temperature raise at each top of the $\mathrm{SiC}$-ceramic rod is below $30{ }^{\circ} \mathrm{C}$ at 2.5 $\mathrm{kW}$ average rf power. In actual operation, the inlet water temperature is around $30{ }^{\circ} \mathrm{C}$, so that the absorber rod temperature will be increased to close to $60{ }^{\circ} \mathrm{C}$. Good frequency response was obtained in low power measurements as shown in Figure 8. 


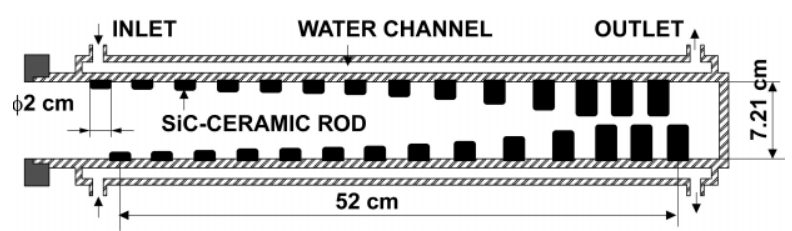

Figure 7: End and Side cut-away views of the SiC-dummy-load. The SiC-ceramic absorbers are the black objects brazed on the narrow side $(3.4-\mathrm{cm})$ of the conventional S-band rectangular wave-guide. All $\mathrm{SiC}$-ceramic absorbers have the same $2-\mathrm{cm}$ diameter.

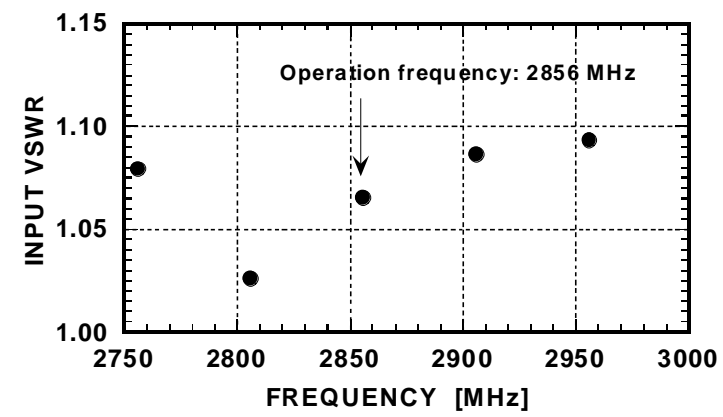

Figure 8: Over-all frequency response of a high power SiCceramic dummy-load measured at low power level.

\section{EXPERIMENTAL RESULTS}

Figure 9 shows the high power test stand for the dummyload. It is comprised of an S-band 80-MW klystron system, connecting wave-guide system and vacuum pumping system. The base vacuum pressure of $1 \times 10^{-6} \mathrm{~Pa}$ was achieved by an ion-pump. A cold cathode gauge (CCG) was used in the vacuum interlock system during rf test.

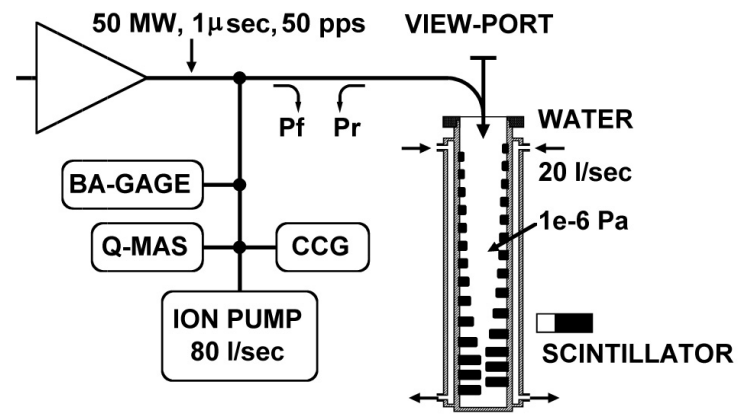

Figure 9: High power test stand of SiC-ceramic dummy-load.

The high power operation was carried out while monitoring the vacuum pressure, $\mathrm{x}$-ray signal and $\mathrm{rf}$ power levels at various points in the system. The forward rf power from the klystron and reflected rf power from the SiC-dummy-load were measured with two Beth-hole couplers. The x-ray signal as measured by a scintillator was used to monitor discharge breakdown in the dummyload. A viewing port was also used to observe visual conditions, such as frequent discharging.

After a total operation time of 100 hours, the input rf power was increased to $50-\mathrm{MW}$ with a $1 \mu \mathrm{sec}$ pulse width and 50-pps repetition rate as shown in Figure 10. As can been seen, the reflected $\mathrm{rf}$ power is only $98-\mathrm{kW}$, which corresponds to an input VSWR of around $1: 1.1$ at the maximum operating specification for this model [6].
Further there was no breakdown signal from the scintillator. At this time, the vacuum pressure of $2 \times 10^{-6}$ $\mathrm{Pa}$ was achieved during rf power turn on.

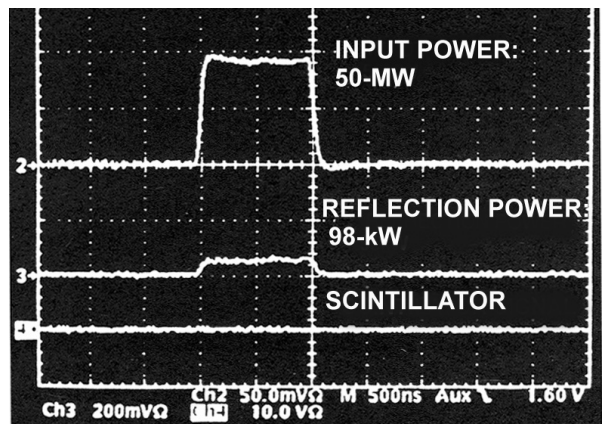

Figure 10: A typical waveforms of the SiC-dummy-load high power test 50-MW, 1- $\mu$ sec and 50-pps.

The temperature sensitivity of the SiC-ceramic absorber was studied by measuring the input VSWR as a function of cooling water flow rate as shown in Figure 11. It is clear that the SiC-ceramic absorber is not sensitive to its temperature of operation.

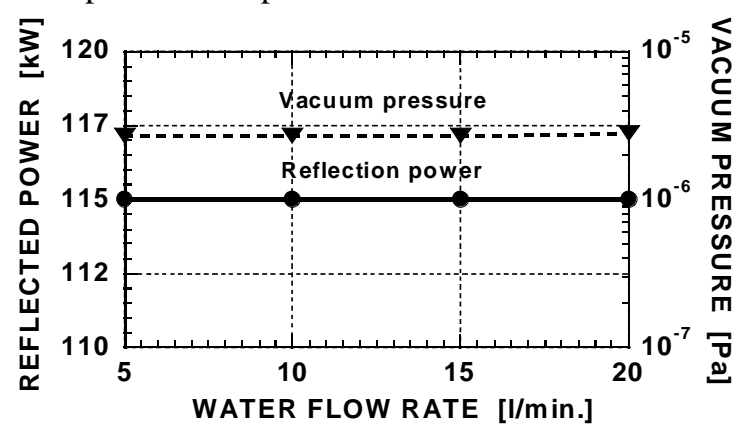

Figure 11: Temperature sensitivity check of the SiC-ceramic type high power dummy-load at 2856-MHz.

\section{CONCLUSIONS}

We have confirmed the design and operation of a new type high power dummy-load using SiC-ceramic absorber. The load is improved in using an indirect cooling method to increase reliability. The first model was successfully operated at 50-MW of rf power $(1-\mu \mathrm{sec}$ and 50-pps for a $25-\mathrm{kW}$ average power). Thus, we may conclude that this SiC-ceramic dummy-load can provide the same reliability as the conventional metal type load.

\section{REFERENCE}

[1] H. Matsumoto, "Application of the SiC-ceramic for Microwave Absorber" (in Japanese), Proc. of the Linac Meeting in Japan, 1983.

[2] JLC group, “JLC-1”, KEK Report 92-16, December, 1992.

[3] Y. Igarashi, S. Yamaguchi and A. Enomoto, "Development of a Dummy-load", KEK Report, 98-12.

[4] R. Enomoto, "SiC powders for the Sintering material", internal report (in Japanese) of IBIDEN Co., Ltd., 1982.

[5] S. Morita and H. Matsumoto, "Development of the S-band High Power RF load" (in Japanese), Proc. of the Linac Meeting in Japan, 1995.

[6] W. H. Hwang et al., "High Power rf performance Test of an Improved Load", Proc. of International APAC98, Japan, 1998 